\title{
Agency Theory: Can it be Used to Strengthen IT Governance?
}

Shaun Posthumus and Rossouw von Solms

\begin{abstract}
In recent years it has become questionable whether corporate boards are able to direct and control IT effectively. There seems to be a general lack of boardlevel information regarding IT which may lead to ineffective governance over it. The aim of this paper is to demonstrate how this scenario relates to the agency problem and how agency theory may be used to offer a theoretical framework for addressing IT-related issues more effectively at board level.
\end{abstract}

\section{Introduction}

The board of directors is generally responsible for defining an organization's overall mission and vision as well as setting its overall strategic direction so that the organization can achieve its goals (vision) and accomplish its purpose (mission). The strategic direction is usually implemented and maintained through a system of directing and controlling. [7] describe this as the direct-control cycle, claiming it to be central to corporate governance.

\section{Directing and Controlling}

A board issues directives on how an organization should function. These directives need to be translated into organizational policies, standards and procedures, which

\author{
Shaun Posthumus \\ Nelson Mandela Metropolitan University, PO Box 77000, PORT ELIZABETH, South Africa, \\ 6031, e-mail: shaun.posthumus@nmmu.ac.za \\ Rossouw Von Solms \\ Nelson Mandela Metropolitan University, PO Box 77000, PORT ELIZABETH, South Africa, \\ 6031, e-mail: rossouw.vonsolms@nmmu.ac.za
}


will enable strategic, tactical and operational alignment with the company's corporate vision and mission. The board also needs to control an organization by ensuring that there is compliance with all directives, policies, standards, procedures and any relevant laws and regulations [7]. Therefore, to properly control (i.e., manage), thus ensuring compliance with directives and policies, there exists a need to measure. In order to measure, there exists a need to identify and collect the correct information to measure against [7]. Any directive issued by the board which cannot be measured in some particular way is of little value because compliance and adequate control cannot be achieved [7]. The board should extend this strategic directing and controlling responsibility into IT to ensure that it supports the corporate vision and mission. This can be accomplished through IT governance.

\section{IT Governance}

IT governance is concerned with aligning IT with an organization's vision, mission and corporate strategy, thus achieving a link between IT and the business. IT governance builds structure around how organizations typically align their IT strategy with the business strategy, ensuring that they remain on course to accomplish their strategies and goals, and put into practice effective means to measure IT's performance [6]. Achieving adequate control over IT is necessary, but it is not a simple task. There still exist many problems that need to be addressed before IT governance will become effective in fulfilling its intended purpose.

[5] claim that most boards remain fairly ignorant as far as IT spending and strategy is concerned. Very few grasp the degree to which their organizations depend operationally on IT systems or the degree to which IT participates in forming business strategy. Ultimately, a lack of board-level oversight for IT activities is unsafe because this creates similar risks to not properly auditing its books would [5]. [2] states that "busy executives and board members need more specific guidance on how to achieve that vaunted goal of effective control". A practical approach to acquiring such guidance would focus on examining how similar issues, not specifically related to IT, have been addressed. Thus, exploring the practices and theories implemented in other disciplines may be beneficial. One theory that may be of potential use is agency theory.

\section{Agency Theory}

Agency theory is concerned with the "ubiquitous agency relationship" in which one party (i.e., the principal) assigns tasks to another party (i.e., the agent) [1]. The agency problem arises due to a conflict of interest between the principal and the agent in terms of work that has been delegated to the agent by the principal. This occurs because the principal and agent may have differing levels of risk acceptance 
[1]. Additionally, it may be difficult for the principal to verify that the agent has behaved in an appropriate manner due to moral hazard and adverse selection [1]. Moral hazard refers to the general lack of effort applied by the agent in carrying out his/her tasks. Adverse selection refers to the falsification of ability by the agent. It is important to address these issues between the principal and the agent to resolve the agency problem effectively.

Without appropriate governance mechanisms in place to acquire necessary information about agent behaviour, the agent is more likely to act in a self-interested way [1]. [1] explains that an agent's actions can be revealed to a principal through the use of information systems such as budgeting systems, reporting procedures, the board of directors, and additional layers of management. Additionally, the principal can contract on the results of the agent's behaviour. This is achieved by measuring the proficiency of their work which motivates the agent to align his/her interests with that of the principal [1]. Furthermore, task programmability can also affect the ease of measuring the agent's behaviour while they carry out a task. [1] claims that known means/end relationships (i.e., task programmability) enables agent behaviour control, as well as crystallized goals (i.e., measurable outcomes), which then enable the principal to control outcomes. An important point to consider would be how the resolutions to the agency problem could be applied to IT governance to offer a means of addressing its many challenges.

\section{IT Governance and Agency Theory}

Agency theory may be applied to IT where the board (i.e., the principal) delegates responsibilities for IT to management (i.e,. the agent). Their relationship, as [4] put it, can be explained through the metaphor of a contract, which, in this case, could be linked to a policy issued by the board that governs the use of IT within an organization. This policy wold then be implemented by middle management through the development of procedures that explain how to comply with policy. Furthermore, middle to low level management would then draw up HR contracts and employees would normally also attend a Security Education Training and Awareness (SETA) course and they would have to sign off that they will comply with the procedures that represent the implementation of policy.

However, since many boards are in the dark about IT-related issues, they may not be able to verify that the IT-related decisions and actions of management effectively portray the best interests of the organization. This may be due to moral hazard and adverse selection, explained through agency theory. Moral hazard may occur because the board may not necessarily be involved in ensuring that IT delivers its said value. Additionally, adverse selection may occur because the board may not know the full degree of the organization's reliance on IT. Thus, it may not be able to certify that management is ensuring that IT is aligned effectively with the organization's business goals. Management could be making IT strategy-related decisions that may not fully support the organizational strategy due to the lack of 
board-level knowledge and involvement. Thus, it is important to ask: "How can a board acquire the essential information needed to gain such control and ensure that management's actions are aligned with the best interests of the organization in terms of IT strategy?"

The solutions to the agency problem provide a possible means to answering this question. In this regard, the concepts of monitoring and measuring play significant roles in helping the board to attain the much needed information required to direct and control effectively and reduce a conflict of interest in the sense that IT may not be aligned with business strategy. Therefore, the board should monitor the actions and decisions of management and intervene, where necessary, to maintain alignment. Furthermore, it should also measure how IT is performing in order to gauge whether value is being produced. This would serve to mitigate the problems of moral hazard and adverse selection. Monitoring and measuring provide a board with information about what is currently taking place in terms of its IT strategic direction in the organization. This information also enables the board to become comprehensive in terms of its own and management's responsibilities to keep IT aligned with the business goals. Thus, the concept of task programmability, discussed in agency theory, also plays a role as it enables behaviour control as well as crystallized goals (i.e., outcomes that are measurable) and outcome control, which [1] has claimed.

\section{Conclusion}

The [3] states that the aligning of IT investments with business strategy is one of the largest issues organizations currently face. It is important that organizations implement appropriate governance over IT because many do not have formalized structures in place to ensure IT and business alignment [3]. Agency theory can be used to achieve this by offering a simple proven theoretical framework that merges the interests of management and the board to ensure that IT fully supports the organization's strategic direction.

\section{References}

1. Kathleen M. Eisenhardt. Agency Theory: An Assessment and Review. Academy of Management Review, 14(1):57 - 74, 1989.

2. Gary Hardy. Using IT Governance and COBIT to Deliver Value with IT and Respond to Legal, Regulatory and Compliance Challenges. Information Security Technical Report: Legal, Regulatory and Compliance Aspects of Information Security, 11(1):55 - 61, 2006.

3. IT Governance Institute. IT Governance Domain Practices and Competencies: IT Alignment Who Is in Charge?, 2005.

4. M. Jensen and W. Meckling. Theory of the firm: Management behaviour, agency costs, and ownership structure. Journal of Financial Economics, 3:305 - 360, 1976.

5. Richard Nolan and F. Warren McFarlan. Information Technology and the Board of Directors. Harvard Business Review, 2005. 
6. Karen D. Schwartz. Abc: An introduction to it governance. [WWW document]. URL http://www.cio.com/article/111700, 2007.

7. R. Von Solms and S.H. Von Solms. Information security governance: A model based on the direct-control cycle. Computers and Security, 25:408-412, 2006.

\section{ACKNOWLEDGEMENTS}

The financial assistance of National Research Foundation (NRF) toward this research is hereby acknowledged. Opinions expressed and conclusions arrived at are those of the authors and not necessarily those of the National Research Foundation. 